\title{
Arte marcial e esporte: um estudo etnográfico sobre uma equipe de judô de Pelotas -RS
}

\author{
Arisson Vinícius Landgraf Gonçalves* \\ Raquel da Silveira ${ }^{* *}$
}

\begin{abstract}
Resumo: Em meio à diversidade de significados que as lutas possuem, um dos aspectos que chama atenção é vê-las enquanto uma modalidade esportiva em ascendência na atualidade. Assim, com o objetivo de compreender os significados que são atribuídos às lutas por seus praticantes, realizamos um estudo etnográfico com uma equipe de judô da cidade de Pelotas/RS. Durante os oito meses de observações foi possível perceber que o judô praticado pelo grupo se encontra em um constante período de transformação de significados, que estabelecem vínculos às orientações culturais orientais e à racionalização da prática em função de um processo de esportivização.
\end{abstract}

Palavras-chave: Lutas. Estudo etnográfico. Processo de esportivização.

\section{INTRODUÇÃO}

Ao se falar sobre lutas, bem como sobre seus significados, abre-se uma discussão acerca das possíveis definições dessas práticas corporais. As lutas estão em várias esferas do cotidiano das pessoas: são praticadas nos momentos de lazer ou como uma atividade física; podem ser consideradas como defesa pessoal e até

\footnotetext{
"Mestre em Educação em Ciência: Química da vida e Saúde (FURG) E-mail: arissonvinicius@yahoo.com.br

"Docente na Universidade Federal do Rio Grande (FURG). E-mail: raqkarate@hotmail.com
} 
mesmo enquanto um recurso disciplinador (moderador da agressividade), o que faz com que seus praticantes muitas vezes as assumam como um estilo de vida. Mas o que mais chama atenção é ver as lutas enquanto uma modalidade esportiva em ascendência na atualidade. O judô, o taekwondo e o karatê ${ }^{l}$ são exemplos mundialmente conhecidos enquanto esporte.

Assim, podemos dizer que as lutas se configuram pela diversidade dos significados que a elas são atribuídos. Se no início do século XX era possível caracterizá-las a partir da preparação para a guerra, para o confronto físico orientado por determinadas correntes filosóficas e religiosas do Oriente, atualmente, está cada vez mais difícil enxergá-las apenas dessa maneira, pois foram sendo apropriadas pela sociedade ocidental do século XX e "desenvolvidas das mais diferentes formas e, em alguns casos, contrariando até mesmo as suas raízes" (MARTA, 2010, p. 25). O interessante é que a mesma diversidade de significados que as mantém enquanto práticas corporais aceitáveis na sociedade, também produz uma determinada noção de tradição em torno delas. Nesse sentido, fazemos uma analogia das lutas com a ideia cunhada por Hobsbawn, de "tradição inventada.". Segundo esse autor,

entende-se [por tradição inventada] um conjunto de práticas regulamentadas por regras tácita ou abertamente aceitas; tais práticas de natureza ritual ou simbólica, visam inculcar certos valores e normas de comportamento através da repetição, o que implica, automaticamente, uma continuidade em relação ao passado (HOBSBAWN, 1997, p. 9)

Hobsbawn (1997, p. 10) destaca que essa continuidade com o passado pode ser "bastante artificial", pois a partir das mudanças da sociedade com a modernidade, muitas tradições tiveram que mudar para continuarem existindo. Assim, é necessário que essas tradições se modifiquem conforme o contexto em que estão inseridas. Nessa perspectiva, as lutas não são diferentes. Mesmo sendo entendidas

${ }^{1}$ Consideramos neste artigo as lutas que possuem vínculos culturais com o extremo oriente. Isso não significa ignorar a existência de outras práticas corporais reconhecidas como lutas provenientes de outras regiões. Apenas nos limitamos a esse recorte para melhor refletir sobre o tensionamento existente entre os diferentes significados que envolvem essas práticas. 
como práticas esportivas, educativas ou atividade física, seu reconhecimento se dá por determinados aspectos formais e rituais que referenciam um passado. É isso que faz delas uma tradição inventada. Ao considerar que essas práticas estão passando por um processo de esportivização ${ }^{2}$, que se baseia no controle da violência conforme os princípios do processo civilizador de Elias e Dunning (1992), a finalidade de preparação para a guerra e suas orientações filosóficas podem não fazer mais sentido para a sociedade moderna, por isso elas se transformam, assumem outros significados. Mas não podemos negar que a racionalização característica do esporte moderno divide espaço com o passado, que por sua vez, possibilita que as lutas, de alguma forma, continuem ligadas à uma determinada cultura oriental.

Damo, Oliven e Guedes (2008, p. 9) afirmam que "nomear certas práticas como esportivas pressupõe reconhecer nelas um vínculo com o ideário moderno, civilizado, disciplinado, codificado, espetacularizado," no caso das lutas consideradas olímpicas, esse vínculo com o ideário esportivo é reconhecido através de características que nem sempre estiveram associadas a elas. A forma na qual são organizadas, regulamentadas e praticadas possuem elementos comuns a diversas modalidades esportivas da atualidade. As federações, as regras e a ênfase no treinamento desportivo são evidências dessa relação. Por isso, consideramos esse tema pertinente a ser estudado no universo acadêmico, já que reconhecê-las enquanto modalidades esportivas geram divergências entre os estudiosos da Educação Física.

Partimos do pressuposto que as lutas, enquanto tradição inventada, se modificam para se manterem na atualidade, seja reforçando um passado vinculado ao oriente ou assumindo um modelo esportivo moderno. Nosso objetivo com esse estudo é compreender quais são essas modificações que ocorrem com as lutas. Portanto, pretendemos contribuir para o entendimento do que são as lutas hoje, e para isso optamos por apreender os significados que são atribuídos às lutas por seus praticantes.

${ }^{2}$ Ver GONZÁLEZ; FENSTERSEIFE, 2005. 
A partir de uma equipe de judô da cidade de Pelotas/RS, procuramos responder algumas questões de pesquisa: (1) Quem são os praticantes? (2) Quem ministra as aulas? (3) Como acontecem as aulas? (4) Como eles reconhecem o judô que praticam?

Nesse sentido, construímos este artigo, que primeiramente versará sobre a metodologia de pesquisa utilizada e após apresentará as discussões desenvolvidas a partir das informações obtidas na pesquisa de campo e na produção acadêmica existente sobre a temática.

\section{ETNOGRAFIA: UM TECER DE RELAÇõES}

Acreditamos que quando se objetiva relacionar alguns fenômenos sociais e o cotidiano vivenciado por seus atores, é sugestivo examinar a realidade "de perto e de dentro"3, se possível fazendo parte dela. Magnani (2002) traz a relação existente entre investigador e o seu universo de pesquisa em um mesmo plano, de modo a possibilitar, muitas vezes, a revelação de faces obscurecidas quando enquadrados por procedimentos metodológicos menos flexíveis.

Para Oliveira (2006), a pesquisa etnográfica é sustentada por elementos como o saber olhar, ouvir e escrever, que se complementam de forma a transformarem o confronto de informações entre pesquisado versus pesquisador, em um verdadeiro "encontro etnográfico" (OLIVEIRA, 2006, p. 24). Ao considerar atos tão característicos da etnografia, o autor enfatiza a complexibilidade existente entre a mediação cuidadosa das relações que se estabelecem com o campo de pesquisa e a escrita filtrada e minuciosa que deve traduzir essa convivência que, de acordo com Winkin (1998), faz da etnografia ao mesmo tempo disciplina científica e criação artística.

\footnotetext{
${ }^{3}$ Magnani em seu texto "De perto e de dentro: notas para uma etnografia urbana" reflete sobre a etnografia enquanto método de trabalho característico da antropologia usado de forma a possibilitar a compreensão do fenômeno urbano.
} 
Nessa perspectiva, Geertz (1989, p. 15) aponta uma característica importante do estudo etnográfico, a "descrição densa"4 , que não significa apenas a riqueza dos detalhes observados no campo de pesquisa, mas sim, a interpretação dos acontecimentos filtrados pelo olhar, e a compreensão do pesquisador que transcreve intenções, vontades, sentimentos, argumentos e explicações durante sua investigação. Para isso, se faz necessário um conjunto de instrumentos metodológicos responsáveis por mediar o material empírico e as interpretações do observador.

Ressaltamos um dos instrumentos que viabiliza o acontecimento etnográfico, a observação participante. Assim, tal procedimento torna possível investigar uma realidade a partir da convivência e interação com a mesma, fazendo da utilização do corpo não apenas um objeto, mas "instrumento de investigação e vetor do conhecimento" (WACQUANT, 2002, p. 12).

A metodologia deste trabalho foi concretizada através de oito meses que resultaram em trinta idas a campo com, aproximadamente, quatro horas de duração cada, registradas em um diário de campo 5 . Outro instrumento utilizado e que veio aprofundar essa relação investigativa foram entrevistas semi-estruturadas realizadas individualmente com três membros do grupo, selecionados com base no período de convivência que se estabeleceu: (1) com o professor de judô, (2) um pai de aluno que também pratica judô no grupo e (3) uma aluna que frequenta assiduamente os treinos.

\footnotetext{
${ }^{4}$ Geertz utiliza uma noção de Gilbert Ryle e exemplifica a descrição densa considerando dois garotos piscando o olho direito: "Num deles, esse é um tique involuntário; no outro, é uma piscadela conspiratória a um amigo". Com essa exemplificação Geertz conclui que uma simples ação, como a de piscar o olho, pode possuir diferentes significados que só conseguimos distinguir ao considerar o contexto do acontecimento (GEERTZ, 1989, p. 16).

${ }^{5} \mathrm{O}$ trabalho de campo foi realizado pelo primeiro autor do artigo que observou, aprendeu e praticou judô com o grupo investigado.
} 


\section{AS PRÁTICAS CORPORAS DE LUTAS NO UNIVERSO PESQUISADO: ENTRE O ESPORTE E AS ARTES MARCIAIS}

Para viabilizar a escolha do campo de investigação, realizamos uma busca por escolas e academias nas quais fossem desenvolvidas práticas de lutas como judô, taekwondo ou karatê. Modalidades como essas foram priorizadas por possuírem elementos que caracterizam a situação de algumas lutas, conforme abordado anteriormente, pois estas, hoje, são comumente reconhecidas, tanto por suas características culturais orientais, quanto por seu formato esportivo. Portanto, dentre os locais e grupos encontrados, e possíveis para tornarem-se lócus da investigação, o escolhido foi uma equipe de judô que desenvolve suas atividades em uma escola localizada no centro da cidade de Pelotas/RS.

O grupo é constituído por três turmas: a primeira composta por alunos matriculados nas séries iniciais do ensino fundamental da Escola Futura ${ }^{6}$, à qual a equipe de judô está vinculada; a segunda turma é formada por jovens matriculados não só nessa escola, ou seja, também pertencentes a outras instituições de ensino; por fim, a terceira turma é integrada por jovens e adultos interessados na prática da modalidade.

Entre os praticantes é possível perceber a heterogeneidade de interesses que os levam a fazer parte dessas turmas. As crianças principalmente seus pais - buscam uma atividade dinâmica, desafiadora e divertida, aliada a uma prática com características educacionais, enquanto arte marcial advinda de uma cultura que valoriza o autocontrole e a disciplina. Os jovens e adultos valorizam a prática de uma atividade física vinculada à luta corporal, mas, principalmente, aderidas a códigos que sistematizam a prática possibilitando a competitividade moldada pelo ideário esportivo.

\footnotetext{
${ }^{6}$ Nome fictício dado à instituição de ensino em que a equipe de judô está vinculada. As aulas ocorrem em espaço cedido por esta escola e atendem tanto alunos matriculados no ensino regular dessa instituição quanto pessoas sem nenhum vínculo, mas interessadas em praticar judô.
} 
Percebe-se que essa proximidade com o formato esportivo do judô se dá por um conjunto de fatores que envolvem o interesse dos praticantes, o ambiente em que ocorrem suas práticas e as principais características das aulas, ou seja, do que é transmitido aos praticantes através dos conhecimentos e conceitos do Sensei ${ }^{7}$.

Contudo, a procura pela luta também acontece devido ao aspecto moral, o qual Barreira e Massimi (2006) associam a uma doutrina, indo além dos movimentos corporais ao valorizar aspectos culturais diferentes dos que constituem a sociedade ocidental. Um exemplo disso é que, na equipe investigada,

muitos pais procuram o judô como forma de contribuir na disciplina de seus filhos, intervindo no comportamento dos alunos não só na escola, como em suas casas com seus familiares. (Diário de Campo 15/04/09).

Porém, na fala de alguns praticantes e do Sensei, é notável que a simpatia por essas características da modalidade divide espaço com outros aspectos também constituintes dessa prática. Quando questionado sobre o interesse que o motiva a praticar judô, o Sensei comenta:

Eu conheci o judô aos seis anos, através do meu pai que me levou numa academia, escolhi o judô porque eu gostei quando visualizei o movimento que o pessoal estava fazendo. [...] Eu sempre fui uma criança muito ativa e em bastante contato com o corpo, em derrubar, brigar, sempre tive bastante influência disso por ter visto na televisão. Aí eu cheguei na academia e eles estavam fazendo um combate, se agarrando, puxando, se derrubando e eu achei que aquilo ali era pra mim. Foi uma coisa que eu pensei: é isso aí que eu quero! (Entrevista realizada em 23/04/09).

\footnotetext{
${ }^{7} \mathrm{O}$ termo Sensei significa professor, popularmente o de Artes Marciais, mas é utilizado de forma geral para se referir a pessoas com maior conhecimento sobre determinado assunto. Para a equipe observada, Sensei é o nome utilizado para que os alunos se refiram ao seu professor.
} 
Já Joana ${ }^{8}$, uma das alunas mais dedicadas do grupo, deixa explicito seu interesse pelo aspecto competitivo do judô, dentro de uma prática pertencente a um formato esportivo institucionalizado. Quando questionada sobre o que a motiva a praticar, ela responde:

Joana: Acho que foi a competição

Entrevistador: E tem alguma imagem que tu lembras que tenha te marcado nesse início?

Joana: Tem, a imagem que me chamou mais atenção assim, na primeira vez que eu vi o judô foi quando eles pegaram o kimono, assim, e começaram a derrubar e derrubar, e aí eles iam depois pra hora do randori (luta)... E aquilo me marcou muito, todas as noites eu sonhava com aquilo, todas não, mas sempre que eu lembrava, eu sonhava (Entrevista realizada em 25/09/09).

Durante a pesquisa, percebeu-se a presença de pelo menos duas faces do judô que coexistem em um mesmo espaço e que criam um significado diferente daquele em que o judô foi criado e diferente também da configuração esportiva moderna. Essas faces mesclam os interesses por uma prática esportiva e a busca por uma atividade ritualística, caracterizada pelo vínculo que essa prática estabelece com o Oriente, que por sua vez, é produzido pelo olhar ocidentalizado dos praticantes. Conforme a obra de Said (2007) uma noção de "oriente como invenção do ocidente" (p. 1), que sempre é referido como algo misterioso, místico e exótico.

Ao considerar o ambiente em que se realizam as aulas/treinos do grupo estudado, é interessante destacar alguns detalhes que marcam esse momento de multiplicidade de significados ou, seguindo a analogia com Hobsbawm, que marcam as mudanças que essa "tradição inventada" está passando para poder se manter. A sala, por exemplo, possui um dojô ${ }^{9}$ amplo, essencial para modalidade. $\mathrm{Na}$ parede de frente para o espaço em que ocorrem as aulas está o

\footnotetext{
${ }^{8}$ Todos os nomes dos informantes são fictícios.

${ }^{9}$ Área de treinamento e de combate. É constituído por um conjunto de tatames encaixados e que ajudam a amortecer o impacto das quedas.
}

Movimento, Porto Alegre, v. 18, n. 02, p. 129-147, abr/jun de 2012. 
retrato do Mestre Jigoro Kano, criador das técnicas do judô, que representa a hierarquização do conhecimento ritualizado na saudação que caracteriza o início e o fim de cada aula, e que expressa uma ligação com o passado, ou seja, com uma determinada origem da luta. Por outro lado, todos esses elementos que remetem a uma prática culturalmente japonesa dividem espaço com imagens de combates em grandes eventos esportivos e fotografias de renomados atletas profissionais dessa modalidade.

\section{As SAUDAÇÕES, AS ROUPAS E A HIERARQUIA: O JUDÔ E A INVENÇÃO DO SEU PASSADO}

[...] o Sensei dá uma voz de comando e os meninos rapidamente se dispõem em uma fila, todos ajoelhados e de frente para o Sensei, distribuídos por ordem de graduação. Como sempre, o aluno mais graduado realiza a saudação inicial no idioma japonês, primeiramente à imagem do mestre Jigoro Kano e em seguida ao Sensei. Assim, todos inclinam o tronco olhando para o chão simbolizando o respeito ao ambiente da prática, ao mestre criador do judô e ao próprio professor (Diário de Campo 20/05/2009).

Conforme o trecho do diário de campo, as lutas, principalmente as de origens orientais, são carregadas de religiosidade e orientações morais que caracterizam não só a sua prática, como também, um estilo de vida de alguns praticantes ao remontarem elementos de determinadas culturas. Contudo, é importante destacar que modalidades de lutas que conhecemos hoje não são as mesmas de tempos remotos, ou seja, são adaptações e invenções de movimentos corporais e rituais criados e utilizados para guerra, para conflitos religiosos e territoriais de determinado contexto histórico (SOUZA, 2002).

$\mathrm{Na}$ equipe de judô investigada, é possível perceber como os aspectos anteriormente mencionados estão marcados, tanto em seu ambiente geográfico, quanto social, por uma ligação com um passado considerado original e são representados por seus rituais, por suas 
roupas, pela hierarquização do conhecimento através das cores das faixas, pelo respeito à imagem do Mestre Jigoro Kano e até mesmo pelo caráter educador e/ou disciplinador que essas práticas carregam. Apesar dos gestos simbólicos característicos das práticas orientais não serem cobrados dos alunos com tanto rigor, alguns já estão familiarizados com esses rituais, que os reproduzem, como um hábito. Joana é um exemplo de aluna que realiza esses gestos rigorosamente. Em todas as aulas observadas, ela segue um ritual próprio, de maneira individual

[...] chega, e como de costume deixa seus tênis na borda do dojo, realiza o gesto de saudação, vai até o quadro do Jigoro Kano saudando-lhe e, posteriormente, repete o mesmo gesto para o Sensei (Diário de Campo 17/06/09).

Ações desse tipo são repetidas de maneira inquestionável, as crianças, por exemplo, sabem que para entrar ou sair o dojô devem realizar determinados gestos. No caso de Joana, assim como dos mais velhos, esse ritual é encarado como uma forma de preservar certa originalidade da prática, é através desses comportamentos, que os praticantes orientalizam o judô. Dessa forma, o judô não é reconhecido apenas pela maneira de lutar, mas, por um conjunto de elementos, de regras tácitas que são regulamentas e mantidas por repetição de seus praticantes. Retomando a idéia de tradição inventada de Hobsbawm (1997), esses elementos configuram a invenção de uma tradição Oriental, que independente da maneira que se luta o judô, é preservada pelas roupas, pelo respeito à imagem de Jigoro Kano, entre outros padrões de conduta aceitos pelo grupo.

Mas nem todos seguem esses rituais ou estão adaptados a esses elementos tradicionais que fazem parte do universo dessa prática. É interessante observar os alunos menores e a dificuldade que enfrentam em vestirem seus judogis ${ }^{10}$, e até mesmo para amarrarem suas faixas em torno da cintura. Geralmente, nos minutos que antecedem a aula, alguns se atrapalham tanto com a indumentária que recorrem à ajuda do Sensei.

\footnotetext{
${ }^{10}$ Roupa apropriada para a prática do judô.
} 
A pressa dos meninos em trocarem de roupa é tanta que muitos vestem as calças ou o casaco do judogi ao avesso. Parece estranho para eles aquela vestimenta, a maioria precisa da ajuda do professor para amarrar as calças e a faixa corretamente. Mesmo com toda a pressa, imagino que não seria tão difícil, ou estranho, se esses meninos estivessem vestindo uniformes de futebol, por exemplo. (Diário de Campo 29/04/09).

É através de acontecimentos como esses que se torna possível acompanhar como essas características de determinadas lutas fazem parte do cotidiano dessa equipe de judô e, principalmente, o que tais elementos significam para esses praticantes. Em uma aula com os adultos presenciamos uma discussão entre o Sensei e alguns alunos que nos chamou a atenção. Por meio de uma brincadeira eles iniciaram uma conversa sobre o caráter ritualístico que algumas lutas, baseadas na filosofia oriental, assumem:

Marcelo e Roberto ${ }^{11}$ entram no dojo como se estivessem apostado uma corrida para ver quem cumprimenta primeiro a imagem de Jigoro Kano e em seguida o Sensei. (...) O Sensei, que também achou cômico a brincadeira entre os dois, comenta que a prática do judô tem rituais muito rigorosos, como as saudações, a submissão ao mais graduado, não poder entrar atrasado na aula, etc. Mas, não cobra de seus alunos com tanta seriedade. Ele justifica essa característica por gostar do lado competitivo do judô e, principalmente, por ter tido uma má impressão de alguns de seus professores que utilizavam as tradições orientais de forma a hierarquizar o conhecimento sobre a modalidade, realizando suas aulas com base na submissão de seus alunos. (Diário de Campo 23/07/09).

Em situações como essa, a tradição é considerada de forma distinta a outras significações, como a esportiva. As saudações e a indumentária ritualizam uma noção essencialista desejável, preservando um passado do judô. No entanto, isso não significa que

\footnotetext{
${ }^{11}$ Dois alunos integrantes da turma dos adultos: Marcelo é Faixa Branca (iniciante) e Roberto Faixa Verde (considerada uma alta graduação no judô).
} 
ao valorizar determinados aspectos esportivos, o grupo desconsidere uma imagem original desta luta. $\mathrm{O}$ modo que eles exercitam essa prática indica um cuidado de manter uma essência oriental que é produzida a partir do olhar que eles próprios lançam para o Oriente. Em um movimento analítico contrário ao de Stevens (2007), que considera a existencia de uma transformação de determinadas práticas de lutas por um processo de ocientalização, diríamos que estes judocas buscam orientalizar o judô, mesmo que seja no sentido de orientalismo trazido por Said (2007). A relação ritualística estabelecida não se dá pela obrigação, mas, sim por querer uma prática que mantenha uma continuidade com o passado, mesmo que seja através da invenção de tradições assumidas como originais/ orientais.

\section{5 É HORA DO RANDORI ${ }^{12}$ : O JUDÔ EM SEU FORMATO ESPORTIVO}

Na tentativa de compreendermos o que é esporte, concordamos com Elias e Dunning (1992) que este é reflexo de uma ruptura dos jogos e dos passatempos populares praticados na Inglaterra, entre os séculos XVII e XVIII. O esporte surge em meio a um processo civilizador possibilitado por uma nova configuração da sociedade européia. Dessa forma, tais passatempos se diferenciavam de outras práticas corporais devido aos significados a eles atribuídos, tanto por quem os praticava, quanto por quem os assistia.

Ao olharmos para algumas lutas como o judô, a partir dessa concepção de esporte moderno, notamos que essas práticas a priori vinculadas a determinado padrão filosófico e religioso, hoje assumem características esportivas que transformam a maneira de entendêlas. Guttmann (1978), mesmo estando distante da concepção teórica adotada aqui para discutir a noção de esporte, pois possui uma perspectiva histórica de continuidade ${ }^{13}$, nos ajuda a entender o judô em um contexto esportivo quando aponta sete características desse

\footnotetext{
${ }^{12}$ Randori significa o combate físico do judô mediado por suas regras. É o momento mais esperado pelos praticantes. É no randori que os judocas aplicam as técnicas que treinaram.

${ }^{13}$ Ver em Stigger (2005, p. 12) a discussão sobre "História do esporte: entre continuidade e ruptura."
} 
fenômeno cultural: (1) organização burocrática, (2) secularização, (3) racionalização, (4) igualdade, (5) especialização, (6) quantificação e (7) recorde.

Na equipe de judô investigada, algumas dessas características são facilmente identificadas. A organização burocrática, por exemplo, é localizada a partir do vínculo que o grupo possui com uma federação que os orienta e viabiliza seu reconhecimento no Estado. Em entrevista com o Sensei, ele comenta sobre o judô enquanto uma profissão:

$\mathrm{Eu}$ acho que tem o aspecto da federação, que realmente ela cobra. O nível de faixa preta pra que se ministre aulas e que se não for isso, se for uma graduação inferior, que tenha um responsável por trás. E também que essa pessoa esteja vinculada à federação, que os alunos estejam registrados, os professores estejam registrados, filiados à federação, que tenham um local vinculado, ligado à federação. Então, isso já dá um suporte para que essa modalidade tenha um certo respaldo e que se consiga trabalhar como profissão (Entrevista realizada em 23/09/09).

Além disso, a secularização, ou seja, a desvinculação dessas práticas do seu caráter místico, ritual e religioso, e a racionalização - quantificação de resultados, criação de medidas como o recorde e a especialização dos papéis desenvolvidos pelos atletas - são, também, características marcantes no grupo, já que grande parte de seus praticantes valorizam um judô competitivo, institucionalizado e reconhecido enquanto modalidade esportiva.

Quando relacionamos a prática do grupo com as principais características do esporte moderno, é possível identificar que o judô praticado por eles é atravessado por um processo de esportivização. Nesta equipe, praticar judô envolve uma série de fatores que estão além das orientações filosóficas das lutas. Para eles, o judô é considerado uma modalidade esportiva que depende de uma estrutura e de materiais adequados, que viabilizem e direcionem o foco da prática para a participação de competições padronizadas, conforme exemplo: 
O professor deixa o primeiro momento da aula livre para que as crianças possam extravasar suas energias e para que possam demonstrar suas personalidades. "Nesse momento eu deixo livre apenas para observar as crianças e ver as diversas personalidades que constituem a turma. Assim, eu posso ver quais levam realmente jeito para o judô esportivo e quais vêm apenas com intenção de brincar", diz o professor (Diário de Campo 15/04/09).

O fato de um aluno levar ou não "jeito" para a prática do judô, a partir da observação do Sensei, pressupõe uma seleção de qualidades que podem ser desenvolvidas de maneira específica para a competição. Em outro momento o Sensei expressa que é diferenciado o treinamento para atletas em suas aulas:

atualmente, ele tem apenas uma aluna (14 anos) que considera, em suas falas, uma atleta, pois seu treinamento é diferenciado dos outros alunos. Certa vez, o professor conta que precisou separar essa menina das aulas com os alunos da escola, pois sua seriedade e determinação eram tanta que acabou espantando alguns alunos. (Diário de Campo 29/ 04/09).

Por outro lado, não é o fato de possuir atletas de ponta que determina tal processo, mas sim a maneira de organização desse grupo. Durante o período de investigação tivemos a oportunidade de acompanhar um evento competitivo elaborado pela própria equipe, o qual enfatizou o aspecto esportivo dessa prática.

Ao acompanhar a divulgação do evento tivemos contato com uma reportagem da página de esportes de um jornal local que trazia alguns trechos interessantes e que resultaram em algumas reflexões no diário de campo:

A reportagem mostra a diversidade de significados, nos quais, o judô praticado por esses sujeitos assume. Primeiro ele traz a informação de que a equipe acabou o ano de $2008 \mathrm{em} 23^{\circ}$ lugar no Ranking Estadual, disputado por cem equipes. Em seguida está transcrita uma frase do Sensei que diz: "O judô busca benefícios físicos, morais e sociais para seus 
participantes. Esse método de prática física e modalidade esportiva estimulam os princípios filosóficos da cultura japonesa, integrando corpo e mente". Falo em diversidade porque percebo neste pequeno texto dois pontos importantes que norteiam esse trabalho. (Diário de Campo 06/06/ 09).

O trecho acima exemplifica que a prática do judô acompanhada durante os oito meses de investigação demonstra tanto os preceitos filosóficos e rituais das lutas, quanto a influência de um modelo esportivo, os quais, se misturam na constituição desse grupo e acontecem simultaneamente. Porém, nota-se que os laços que ligam essa prática ao ideário esportivo atual são muito mais valorizados.

Esses aspectos relacionados com a organização e administração do grupo frente ao formato esportivo demonstram que apesar de estarmos nos referindo a uma prática de luta, em que a questão da violência seria supostamente referendada, as regras criadas e as instituições representativas do judô enquanto esporte, civilizaram essa prática a partir de um processo de esportivização, semelhante ao realizado com os passatempos populares conforme descreve Elias e Dunning (1992). Contudo não podemos negar que "essas práticas [as lutas] ainda possuem algumas características próprias às quais o entendimento desse processo de esportivização por si só não responde" (MARTA, 2010, p. 30).

Dessa forma, tendo em vista a configuração que esse grupo assume, nota-se que tanto os significados atribuídos, quanto a prática dessa modalidade de luta estão mais próximos de uma prática esportiva e institucionalizada. Entretanto, isso não quer dizer que a tradição, os ritos, a valorização por um passado do judô não esteja presente.

\section{Considerações FinAS}

Pudemos perceber, a partir da etnografia realizada, que as lutas passam por um processo de mudanças em sua configuração. Consideradas enquanto tradições inventadas, consideramos que elas, 
tiveram que se modificar para continuarem existindo. A valorização de um modelo esportivo é, atualmente, uma característica marcante em algumas dessas práticas. $\mathrm{O}$ judô acompanhado nesta pesquisa se encontra entre duas faces: a primeira, representada pela ligação às orientações filosóficas das lutas; e a segunda, demonstrada pela reprodução e pela forte influência de um modelo esportivo.

Durante os oito meses de idas a campo, tivemos a oportunidade de acompanhar, em diversas ocasiões, situações que marcaram a coexistência dessas duas faces. Algumas características da cultura japonesa, presentes em alguns gestos, vocabulário e roupas, demarcam o orientalismo dessa prática corporal. Porém, não se pode negar que os movimentos técnicos, exercícios físicos, conversas entre os praticantes e a própria relação entre professor e alunos são inspirados nos esportes.

O judô, para a grande parte dos componentes do grupo, é entendido como uma modalidade esportiva em que a valorização de um oriente deve ser mantida enquanto uma referência ao passado. Nesse sentido, se justifica a analogia que fizemos com as "tradições inventadas" de Hobsbawn (1997), em que as lutas estão passando por um processo de mudanças, para continuar tendo sentido na sociedade moderna. É a partir de um processo de esportivização que essa mudança vem ocorrendo, sem, contudo, romper com uma noção ritualistica que a caracteriza enquanto oriental. 
Martial art and sports: one ethnographic study with judo team from Pelotas-RS

Abstract: Taking into consideration the diversity of meanings attributed fights, one of the aspects that call our attention in to see those fights as a sport which are in evidence nowadays. In order to understand the meanings that are attributed to those fights by practitioners, we have accomplished an ethnographic study with a judo team from Pelotas-RS. After observing for eight months those fighters it was possible to realize that judo, practiced by the group. It was found out that judo is in a constant period of transformation concerning to the meanings of those fights establishing bonds with the Eastern cultural orientations and the rationalization of the practice according to the sport process.

Key words: Fights. Ethnography. Sport process.

\footnotetext{
Arte marcial y deporte: un estudio etnográfico sobre un equipo de judo de Pelotas -RS

Resumen: En medio a la diversidad de significados atribuidos a las luchas, un de los aspectos que llama atención es ver ellas como una modalidad deportiva en ascendencia en la actualidad. Con el objetivo de compreender los significados que son atribuidos a las luchas por sus praticantes, realizamos un estudio etnográfico con un equipo de judo de la ciudad de Pelotas/RS. Durante los ocho meses de observaciones fue posible percibir que el judo, practicado por el grupo, se encuentra en un constante periodo de transformación de significados que establece vinculos a las orientaciones culturales orientales y la racionalización de la práctica en función de un proceso de deportivización.

Palabras-claves: luchas. Etnografia. proceso de deportivización.
} 


\section{REFERÊNCIAS}

BARREIRA, C.R.A; MASSIMI, M. O caminho espiritual do corpo: a dinâmica psíquica no karate-do shotokan. Mamorandum, n. 11, p. 85-101. 2006. Disponível em: $<$ http://fafich.ufmg.br/ memorandum/a11/barreiramassimi03.pdf.>. Acesso em: 31 ago. 2009.

DAMO. A. S.; OLIVEN. R.G.; GUEDES, S.L. Apresentação. Horizontes Antropológicos, Porto Alegre, v. 14, n. 30, p. 7-17, jul./dez. 2008.

ELIAS, Norbert; DUNNING, Eric. A busca da excitação. Lisboa: Difel, 1992.

GEERTZ, Clifford. A interpretação das culturas. Rio de Janeiro: Guanabara Koogan, 1989.

GONZÁLEZ, Fernando Jaime; FENSTERSEIFER, Paulo Evaldo. Dicionário Crítico de Educação Física. ljuí: [s.n.], 2005.

GUTTMANN, Allen. From ritual to Record: the nature of modern sports. New York: Columbia University, 1978.

HOBSBAWM, Eric; Introdução: A invenção das tradições. In: HOBSBAWM, Eric; RANGER, Terence. A invenção das tradições. 5. ed. Rio de Janeiro: Paz e Terra, 1997. p. 9-23.

MAGNANI, José Guilherme Cantor. De perto e de dentro: notas para um etnografia urbana. Revista Brasileira de Ciências Sociais, São Paulo, v. 17, n. 49, p.1129, jun. 2002.

MARTA, Felipe Eduardo F. A memória das lutas: as artes marciais orientais e a sua presença na cultura corporal de São Paulo. São Paulo: EDUC, 2010.

OLIVEIRA, Roberto Cardoso de. O trabalho do antropólogo: olhar, ouvir e escrever. São Paulo: Editora Unesp, 2006.

SAID, Edward W. Orientalismo: o Oriente como invenção do Ocidente. São Paulo: Companhia das Letras, 2007.

SOUZA, Vinícius Aguiar. Análise de impacto e risco de lesões no segmento superior associadas a execução da técnica de Gyaku Tsuki sobre Makiwara sobre praticantes de karate do estilo Shotokan. 2002. 110 f. Dissertação (Mestrado) - Programa de Pós-Graduação Engenharia Mecânica, Universidade Federal do Rio Grande do Sul, Porto Alegre, 2002.

STEVENS, John. Três mestres do budo: Kano (judô), Funakoshi (Karatê), Ueshiba (aikido). São Paulo: Cultrix, 2007.

STIGGER, Marco Paulo. Educação Física, esporte e diversidade. Campinas: Autores Associados, 2005. 
Arte marcial e esporte: um estudo etnográfico...

WACQUANT, Loic. Corpo e alma: notas etnográficas de um aprendiz de boxe. Rio de Janeiro: Relume Dumará, 2002.

WINKIN, Yves. Descer ao campo. In: WINKIN, Yves A nova comunicação: da teoria ao trabalho de campo. Campinas: Papirus, 1998. p. 129 - 145.

Recebido em: 13.04.2012

Aprovado em: 25.05.2012

Movimento, Porto Alegre, v. 18, n. 02, p. 129-147, abr/jun de 2012. 
